\title{
The role of traditional knowledge policies in Egypt: the case of Wadi Allaqi
}

\author{
Hanaa A. Kandal ${ }^{1}$ (D) Jac. A. A. Swart ${ }^{1} \cdot$ Hoda A. Yacoub $^{2} \cdot$ Menno P. Gerkema $^{1}$
}

Received: 25 April 2020 / Accepted: 29 November 2020 / Published online: 4 February 2021

(c) The Author(s) 2021

\begin{abstract}
Globally, traditional knowledge is at stake, notwithstanding intentions recorded in international policy conventions. Egypt has accepted and ratified several conventions on implementation of traditional knowledge in the fields of environment and sustainable development; yet this implementation is hampered by a lack of concrete plans. Focusing on the Bedouin community in the Southern Egypt protectorate of Wadi Allaqi, this paper investigates whether traditional knowledge plays a role in Egyptian policy, as reflected in policy documents and by interviews with regional stakeholders. We found that local actors of Wadi Allaqi protectorate-involved institutions appreciate the importance of traditional knowledge especially in environmental affairs. It can be concluded that a strengthened position of traditional knowledge in regulation and law should be supplemented by social measures and actions to overcome bureaucratic, geographical, and communicative barriers. Derived recommendations imply that the perspective of the Bedouin community should be taken into account.
\end{abstract}

Keywords Traditional knowledge $\cdot$ Policy $\cdot$ Wadi Allaqi $\cdot$ Egypt $\cdot$ Bedouin stakeholders

\section{Introduction}

Indigenous peoples around the world have secured their livelihood by making use of knowledge and experiences accumulated over generations in close interaction with their environment (Johnson 1992). This so-called traditional knowledge (TK) is usually transmitted through oral traditions and preserved through cultural expressions such as arts, crafts, and ceremonies. They form the basis for local-level decision-making in a variety of activities including hunting, agriculture, health care, food preparation, education, natural resource management, trade and spiritual divination (Drew 2005; Mundy and Compton 1991). Such indigenous or traditional knowledge, skills, and techniques ${ }^{1}$ may contribute to

\footnotetext{
1 Traditional and indigenous knowledge are not interchangeable terms according to some authors (e.g., Mugabe 1998), although others assure that the term "traditional knowledge" (TK) and "indigenous knowledge" (IK) mean the same thing (Sillitoe 1998). Here, we aim not to deal with this issue of terminology and

Hanaa A. Kandal

hanakandal@gmail.com

1 University of Groningen, Groningen, Netherlands

2 Wadi Allaqi Biosphere Reserve, Nature Conservation Sector, EEAA, Aswan, Egypt
} 
sustainable policies concerning the environment and cultural heritage. They may also provide potential valuable sources of information in various disciplines as resource management, conservation, and restoration (Berkes 1999). An example, relevant in the context of this paper, is the rotational grazing strategy, which has enabled Bedouin people to develop a sustainable livelihood in harsh and hostile deserts (Briggs et al. 1993).

The interest in TK, in addition to its value from a cultural history perspective, has expanded among scientists, managers, policy-makers, and development agencies and has become an evolving subject of national and international laws (Anaya 1996). This recognition is reflected in the establishment of international conventions, protocols, guidelines for the protection and inclusion of traditional knowledge in environmental policies. For example, the 1992 Rio de Janeiro Conference recognizes in chapter 26 of Agenda 21 that indigenous peoples have a vital role in environmental management and development because of their traditional knowledge and practices.

However, TK has an intrinsic value and it is the responsibility of the global community to save TK as a cultural heritage. Besides the recognition of the value of TK as a human capacity in the framework of resilience (Berkes et al. 2000), it is an aspect of cultural identity (Walker et al. 2004). Furthermore, TK may be useful in fields like agriculture, medicinal and pastoral plants, hunting and navigation under harsh conditions with restricted resources. For example, the programs that have been launched by the United Nations Development Program (UNDP) and World Bank organizations to promote indigenous peoples' development, stress that socioeconomic development should fully respect the dignity, human rights, and uniqueness of indigenous peoples. Countries in various continents, e.g., South Africa (Green 2007), Canada (Posey 1999), and Peru (Tobin 2004) have recognized the importance of TK and have developed legal frameworks to address and integrate it with other sources of knowledge (CFFS 1997).

In this paper, we consider the role of TK in Egyptian policy paying especially attention to Wadi Allaqi, a hyper-arid area in the south Eastern Desert near the Egyptian Sudanese border. That area is inhabited by Bedouin nomadic tribes and the livelihood of nomads and pastoralists depended on the limited resources of arid lands. Their traditional knowledge of Wadi Allaqi resources is crucial to survive in this environment. These resources satisfy a range of needs and production opportunities, among which food, animal grazing, firewood, charcoal production, building materials, shade and raw materials for medicinal purposes. Only deep knowledge of the uses of these limited resources, combined with knowledge about their management, enabled people to survive in such a hostile environment (Briggs et al. 1993; Belal et al. 1998; Kandal et al. 2016, 2019).

The construction of Aswan High Dam and subsequent formation of Lake Nasser between 1967 and 1972 (Briggs et al. 1993; Belal et al. 1998) have led to changes in the natural resource base of Wadi Allaqi. Further, social-economic changes resulted from the establishment of a new, permanent residence, Wadi Allaqi village, by the Egyptian government in the early $2000 \mathrm{~s}$ at about $16 \mathrm{~km}$ from the lake. These changes led to changes in Bedouin livelihood, their TK, and environmental management strategies with respect to

Footnote 1 (continued)

have chosen for a practical approach by using only the term "traditional knowledge" (TK), in order to avoid a semantic discussion about the meaning of "indigenous." 
grazing and seasonal migration traditions and have also led to agriculture in the close proximity of Lake Nasser (Briggs et al. 1993; Kandal et al. 2016, 2019).

Due to its geographical location, the variety of habitats, and high biodiversity, the area of Wadi Allaqi has been declared as a conservation area by the Egyptian government in 1989 and has received a protected status under the Egyptian Environmental Affairs Agency (EEAA) ever since. In 1993, it was designated as a biosphere reserve under the UNESCO Man and Biosphere Programme (MAB).

Recently, we documented a further loss of TK among Bedouins of Wadi Allaqi (Kandal et al. 2016, 2019). In this paper, we assess whether TK does play any role in national policy documents in Egypt, including strategy and action plans with regard to health, education, economic, and environmental management. In order to get insight into the local situation of Wadi Allaqi, we interviewed relevant stakeholders of regional Wadi Allaqi Biosphere Reserve (WABR) on the implementation of TK by both policy-makers and scientists in the area.

Below, we briefly describe the applied methodology. Accordingly, we present the results along two lines. First, we analyze international agreements on TK and their implementation in Egypt; second, we outline the views of regional Wadi Allaqi Biosphere Reserve (WABR) policy-makers on TK. Finally, in the discussion, we integrate our findings through a SWOT-like analysis to indicate actual strengths and weaknesses as well as future opportunities and threats regarding TK policy in Wadi Allaqi, as a basis of recommendations for future TK policy development in Egypt.

\section{Methodology}

First, we identified relevant sources by desk research, collecting, and analyzing TK-related policy documents in international articles, journal papers, books, conference proceedings, legislation documents, research and educational programs, government publications concerning relevant acts, surveys and handbooks from relevant agencies and NGOs. A specific focus was on national documents and reports of strategies and action plans of conservation and TK in Egypt by the Egyptian Environmental Affairs Agency (EEAA) and on international agreements explicitly dealing with TK, or more implicitly with the cultural position of indigenous people, which appeared to be relevant for the Egyptian case.

Keywords used for an Internet search were indigenous knowledge, traditional knowledge, Egyptian policy, conservation policy, education policy, agricultural policy, protectorates, Wadi Allaqi, knowledge policies, indigenous people, traditional medicines, strategies for environmental protection, Aboriginal people, environmental education, and integrating traditional knowledge. In addition, we analyzed TK documents in the field of education, especially with regard to the curricula of the faculties of education, agriculture, medicine, and pharmacy of two governmental universities falling under the responsibility of the Ministry of Higher Education and Scientific Research (MoHESR), i.e., the Universities of Aswan and the University of Assiut. The Aswan University is the nearest regional university to the Wadi Allaqi region and houses the Unit of Environmental Studies and Development (UESD). Researchers of the faculties of Science and Social Work of this university have worked in Wadi Allaqi since the 1980s. Until 2012, the Aswan University was a branch of Assiut University, which was established in 1957. However, both universities still cooperate in the disciplines of science, pharmacy, and agriculture. The specific role of TK in the environmental policy of Egypt in general was discussed during an interview with 
Table 1 Mean TK priorities according to representatives from the four societal sectors

\begin{tabular}{llllll}
\hline Aspects & $\begin{array}{l}\text { Governmental } \\
\text { sector }(n=8)\end{array}$ & $\begin{array}{l}\text { Academic sector } \\
(n=7)\end{array}$ & $\begin{array}{l}\text { Private sector } \\
(n=1)\end{array}$ & $\begin{array}{l}\text { NGO sector } \\
(n=1)\end{array}$ & $\begin{array}{l}\text { Overall } \\
\text { score } \\
(n=17)\end{array}$ \\
\hline Environmental & 5.5 & 6 & 5 & 5 & 5.6 \\
Religious & 4.9 & 5.6 & 4 & 6 & 5.2 \\
Health & 5.1 & 4.9 & 6 & 2 & 4.9 \\
Economic & 4.8 & 4.4 & 7 & 3 & 4.7 \\
Cultural & 4.4 & 5.3 & 3 & 5 & 4.7 \\
National identity & 2.4 & 4.3 & 2 & 7 & 3.4 \\
Historical & 1.9 & 3.6 & 1 & 1 & 2.5 \\
\hline
\end{tabular}

Prof. Moustafa M. Fouda, ex-director of Nature Conservation Sector (NCS), EEAA, the Ministerial Advisor on Biodiversity Egypt, and instrumental in several international conventions (e.g., Biodiversity, CMS, RAMSAR). Topics were both the relationship between TK and conservation at national level as well as the relevance of TK for Egyptian environmental policy-makers.

Second, we interviewed for our study in Wadi Allaqi representatives from the regional institutions that deal with the Wadi Allaqi protectorate of the Aswan governorate. These institutions comprise the environmental authority Wadi Allaqi Biosphere Reserve (WABR) at its regional branch office in Aswan and local administrative authorities, Aswan University staff, a private company working in Wadi Allaqi and an NGO (Supplementary materials Fig. 1 and Table 1). As we could only interview one person from these two latter sectors, their scores must be considered as personal views. The governmental sector implements national policies in the region of Allaqi Village with regard to environmental issues, education and cultural affairs, and health services. The academic sector not only contributes to education and scientific research, but also supports in cooperation with the EEAA, community-based efforts to increase social awareness of environmental and health issues (e.g., measures against bird flu). The private sector we interviewed has an interest in mining, processing, and marketing and provides job opportunities. Finally, the NGO involved supports Wadi Allaqi Bedouins in protecting their TK heritage.

A total of seventeen interviews with local actors were conducted in the city of Aswan, in April-May 2016. All interviews began with asking for a short description of the interviewees' aims, followed by a semi-structured discussion aimed at exploring the opinions of the interviewee about TK in Egyptian law and policy. To assess the weight that interviewees attribute to the different aspects of TK, we displayed a set of possible functions of TK (environmental, cultural, historical, economical, health, religious, national identity) and asked the interviewee to sort them by his/her priority (a shared priority was allowed), see Table 1 . The final questions were related to the role of TK in a legal regulatory framework and to the role and obstacles for using it in his or her organization.

We applied a SWOT-like analysis on our results to identify potential policy elements for the use of TK in Egypt, particularly in Wadi Allaqi. The essential idea of a SWOT analysis is a categorization (in strengths, weaknesses, opportunities, and threats) of characteristics of a development or situation. Making use of the literature, interviews, and reflection as analytic tools, a SWOT analysis not only summarizes results but also can form a starting point for a discussion. The SWOT analysis was first developed in 1966 in the framework 
of corporate planning of organizations (Humphrey 2005) to integrate judgments on the actual situation with that of future perspectives (Osita et al. 2014). Thus, a SWOT analysis identifies strengths that give an advantage over others whereas weaknesses concern the internal vulnerability that should be bypassed or neutralized. Threats and opportunities mainly focus on the external environment of an undertaking. Threats are conditions that could cause serious troubles and need to be replaced by alternatives. Opportunities may contribute to success and should be seized by the undertaking. Our SWOT-like analysis builds upon our previous field research among Bedouins in Wadi Allaqi on the role of TK (Kandal et al. 2016, 2019). As we applied this tool in a policy sector instead of a concrete organization, we prefer the term SWOT-like analysis above SWOT-analysis. Based on this integrated categorization, we formulate recommendations for future Egyptian policy-makers with regard to TK policy in the final part of the discussion.

\section{Results}

\subsection{International agreements, TK, and policy-making in Egypt}

Egypt was one of the ten signatories to the Convention Relative to the Preservation of Fauna and Flora in their Natural State (established in London 1933) which took care of biodiversity, conservation of environmental resources, and natural heritage. This was followed by the accession of Egypt to many international and regional agreements and conventions, for example, the African Convention for the Conservation of Nature and Natural Resources in Algiers in 1968, the Convention on Wetlands of International Importance in 1971, the International Convention on Protection Cultural and Natural Heritage in Paris in 1972, and the Convention on Biological Diversity (CBD) in 1992 (EEAA 1997, 2016; Harhash 2012; Ibrahim 2000).

Table 2 in the supplementary materials shows twelve major international treatises on TK and related cultural heritage aspects of indigenous people in which Egypt has been involved. Egypt was among the early countries to ratify The Hague Convention for the Protection of Cultural Property in the Event of Armed Conflict in 1956, the Convention against Discrimination in Education in 1962, and the Convention for the Safeguarding of the Intangible Cultural Heritage in 2006. The country was a founding member of the African Development Bank and signed and ratified several International Labour Organization (ILO) and UNICCO conventions.

The establishment of the governmental agency of Egyptian Environmental Affairs Agency (EEAA) in 1980 reflects the commitment of Egypt to these international agreements. The task of EEAA has been formulated as the implementation of national environmental policies including conservation of biological resources and natural heritage (Salama 2011). It was followed in 1992 by the establishment of a Nature Conservation Sector (NCS), which is responsible for the management of the National Protected Area Network, nature conservation, management and development of resources (EEAA 2008). It also has to manage the implementation of relevant international agreements and cooperation with international agencies and organizations.

Establishing protected areas is one of the most important strategies in Egypt to protect locations with natural, ecological, and cultural values (EEAA 2006a). A network of 30 protected areas has now been declared, covering more than $15 \%$ of the Egypt's natural and cultural heritage resources (website of the EEAA). Conditions and restrictions of the 
economic development of these areas may be instrumental to sustain traditional knowledge and cultural heritages (e.g., languages, handicrafts) and traditional lifestyles (EEAA 2008).

According to article 151 of the Egyptian Constitution, any international convention signed by the Government of Egypt and ratified by the Egyptian Parliament becomes part of national legislation from the date of its publication in the Official Gazette. Consequently, Egypt has issued a number of laws in line with these international conventions. For example, based on the CBD convention, an action plan was published recognizing the rights of local populations with respect to intellectual properties (EEAA 1998, 2005).

The further recognition of TK can be traced by EEAA policy documents. In 2006, the strong link between biodiversity and TK has been acknowledged, realizing that loss of TK may threaten Egyptian biodiversity. Recognition of the rights of the traditional communities and engaging them in managing their areas could contribute to the protection of natural area (EEAA 2006b). In 2010, the EEAA considered the utilization of traditional knowledge as an adaptation strategy of the coastal zone. Besides scientific input, stakeholders' involvement of indigenous partners in adaptation planning and increased public awareness were considered as important strategies (EEAA 2010). More recently, the EEEA (2015) highlighted the importance of TK of local communities and the necessity of its protection, documentation and usage, as well as the registration of handicrafts and linkages between the cultural and natural heritage in protected areas.

In addition, few initiatives have been taken to maintain, protect, document, and promote TK with respect to natural resource management and mechanisms to promote access and benefit sharing of genetic resources (Medaglia et al. 2014). However, the possible role of TK is not considered in Egypt's national strategy to increase its community's resilience on the risks of climate change (IDSC 2011, 2017) and it does not play a role in conservationrelated studies on Egypt's national heritage (Yacoub 2013). In 2012, a draft law (ABS law) was finalized to regulate TK in relation to access to Egypt's genetic resources based on the Convention on Biological Diversity (CBD) and the Nagoya protocol. However, this draft has not been enacted into law yet (Harhash 2012; Dr. Fouda personal comm.).

Nevertheless, Egypt's fifth national report (EEAA 2014) indicates some successes in Egypt's efforts in biodiversity measures through institutional support and capacity building for conservation, sustainable agriculture, and local community empowerment, recognizing the value of cultural diversity and traditional knowledge. In addition, traditional use of medicinal plants has been documented in Wadi El-Gemal National Park (Mahmoud and Gairola 2013) and in Beni-Suief, Upper Egypt (Abou Zid and Mohamed 2011). Elansary et al. (2015) reveals the TK of species in Alexandria, North Egypt, that could potentially guide the search for new cosmetic products.

The Egyptian Biodiversity Strategy and Action Plan (2015-2030) of EEAA (2016) emphasizes the importance of sincere commitment by local communities and indigenous peoples, and the extension of corroboration with institutional initiatives through harmonization of biodiversity-related policies with legislative programs. As an example, in 2008, the local community in St. Catherine protectorate got involved in the management of natural resources by the NGO St. Catherine Medicinal Plants Association. The local community initiatives in that area have led to schools for herbal studies for local Bedouin children to ensure that the traditional knowledge will be passed on to next generations (Dr. Fouda, personal comm.).

However, such school initiatives seem to be an exception as TK is neither mentioned in Egyptian school programs nor in the programs of medical, pharmaceutical, agricultural, and economic faculties of the Egyptian universities we assessed. Universities, including private universities, and schools fall under control of the Ministry of 
Education (MoE) and have little control on their curricula, program development, and deployment of staff. It is the Ministry's duty to select and distribute textbooks and to control school-based programs. The Ministry of Higher Education (MoHESR) supervises the tertiary level of education and the scientific research, including research plans and curricula. In addition, TK does not seem to play any role in hospital health programs, although $23 \%$ of the Egyptians use medicinal plants (IDSC n.d. 2018).

In summary, one can state that Egypt has accepted and ratified several conventions supporting the implementation of TK in the fields of environment, biodiversity, conservation, and sustainable development. However, TK hardly plays a role in education and research. Despite the establishment of protected areas, the implementation of TK has not fully taken place and the role of local communities is still weak mainly because of a lack of concrete plans (EEAA n.d. 2016). An exception is areas characterized by strategic and security interests and those with touristic potential, e.g., protectorates located in Sinai and the Red Sea area (El-kahki 2010).

\subsection{Views of regionally involved Wadi Allaqi Biosphere Reserve actors}

\subsubsection{Role and meaning of TK}

A majority of the interviewees acknowledged the relevance of TK and its role in society (Table 1). Governmental interviewees described TK as a culture of coexistence with the surrounding environment that can play a role in conservation. As such TK reflects the background of a community transmitted through the generations which should be conserved. Also, academic interviewees agreed on the importance of TK in this respect. One of them described TK as "all written and unwritten knowledge that the individual inherits from the local culture of his community: neighbors, relatives and family." Moreover, this person said, "it has a big role in society because it is the reference to which people will return to and from which they learn." Another academic interviewee viewed TK as the cultural heritage contributing to the upbringing of children and being reflected in their behavior. One academic interviewee pointed to the importance of TK in conserving the national identity, stressing that "who has no past has no present." Other interviewees mentioned the usefulness of TK of medicinal plants for pharmaceutical research. The interviewee from the private sector affirmed the importance of TK, being the legacy of ancestors and reflecting society's perception of events. The NGO interviewee stated "TK is important as it is showing our culture, history and civilization" and "TK has a great role in our life, it conserves our culture and transfers it through generations." On the other hand, a number of interviewees from governmental and academic sectors think that TK is perhaps important to some extent but they also felt that it will not be sufficient for people who are aware of the modern technological society.

As TK may have different functions, we applied a card sorting methodology to assess the relative importance of these functions (Table 1). It appears that the environmental function is seen as the most important function. It is followed by the religious and health functions according to governmental and academic representatives. The economic function of TK has priority according to the representative from the private sector. The historic and national identity functions got the lowest overall priority but they were assigned the highest priority by the NGO. 


\subsubsection{TK and legal regulations}

A majority of the interviewees, four from governmental sector, two from academia, and the representative from the private sector, agree that TK should be reflected in Egyptian laws because regulation could guarantee and enforce its functioning, documentation, and conservation. Several of them argued that TK as part of international legal regulations and conventions like the CBD has already been implemented in Egyptian legislation. According to them, most important is raising awareness through seminars, courses, workshops, and the media. However, one of the governmental participants added that the functionality of TK should be proven first. In contrast, a representative from the governmental sector and two from academia argued that TK needs not to be reflected in legal regulation, but that societal awareness about TK should be increased and that organizations and projects should be adapted to this aim. The interviewee from the NGO agreed with this and added that financial support is more important than legislation.

\subsubsection{The role of TK in the actors' organizations}

Most of the governmental representatives expressed that TK does not play any role in their own organization. Half of the academic interviewees responded similarly, noticed the absence of TK in university programs and strategic plans, or said that a TK perspective is not needed for their own tasks. Nevertheless, in general, they agreed that TK should play a role but that they do not have the authority to place these issues in their assigned activities, which is something that belongs to the field of policy-makers.

In contrast, one interviewee from the governmental sector, three academics, and the ones from the private sector and NGO said that TK does play a role in their organizations, because of the nature of the work in their organizations. For example, one governmental representative reported that TK is used to achieve the protectorate goals and to get in contact with local people. An academic interviewee mentioned that in addition to modern technologies as GIS and digital maps, TK has shown to be helpful in predicting soil compositions by soil colors in the area of Allaqi. The interviewed NGO appeared to be involved in stimulating markets for TK-based handicrafts in Aswan and other places in order to contribute to livelihood of Bedouin women.

The interviewees indicated that many practical conditions limit the implementation or regulation of the use of TK in Wadi Allaqi. One needs an official permission to enter the area which is close to the military area at the Sudan border, and traveling and staying in Wadi Allaqi are rather expensive. Despite these limitations, most interviewees still claimed to be familiar with the Bedouins in Wadi Allaqi because they are hired as guides, guards, or workers during fieldwork. However, it was added that Bedouins do not have much ambition, being reluctant to learn new skills for other work than guarding or guiding. In addition, it appears that working or communicating with the Bedouins is not easy: The Bedouin language is a barrier, and the Bedouin community is isolated and does not accept strangers easily.

In summary, the interviews with the local parties of Wadi Allaq protectorate reveal that most of them appreciate the importance of TK in the Egyptian policy in general and especially in environmental affairs. It also appears that a stronger position of TK in regulation and law is not enough and should be supplemented by social measures and actions. Finally, TK in Wadi Allaqi plays a limited role in the practices of most 
interviewees due to the nature of their work, bureaucracy, the geographically isolated location, and communication barriers with the Bedouin community.

\section{Discussion and conclusions}

Egyptian regulations with regard to biodiversity and natural heritage conservation, sustainable development, and the rational use of natural resources also include the protection of TK, although the concept is not clearly defined or explained. TK is mentioned specifically only in the context of intellectual property issues. The governmental environmental initiatives with regard to TK remain largely symbolic. Gomaa (1997) assumes that these initiatives are designed to attract foreign assistance funds, based on the willingness of foreign institutions to donate money to support environmental measures and policies under the condition that certain standards are met. As Egypt is a developing country with priorities that focus on investments in the contexts of tourism, urbanization, and industrialization (USAID 2010), it may be expected that commercial development is easily prioritized over the protection of environmental issues, including TK issues (Gomaa 1997). Egypt is in this respect comparable to many other developing countries (Medaglia et al. 2014).

On the other hand, managing relationships with indigenous communities has been a new and challenging experience for governments recognizing them as key stakeholders and partners in sustainable development. However, there is a potential tension between policy intentions and a concrete policy framework on one side and activities concerning traditional knowledge of indigenous peoples and respecting their rights to implement TK on the other side. The implementation of TK through policy formulation and development and conservation projects should foster economic, social, and cultural well-being. A common challenge for governments is not only how to manage these conflicting aspects, but more generally, how to integrate indigenous people into decision-making processes as rightful stakeholders in conflictive situations. Many advocate approaches that prioritize partnerships based on recognition, respect, integration, and commitment to justice in relation to indigenous and traditional communities rather than undermining indigenous rights and the knowledge systems that underlie them. (Howitt and Suchet-Pearson 2006; Howit et al. 2012; Wilcock et al. 2013).

The marginal position of TK in Egyptian policy may threaten TK as is illustrated by a decline in knowledge of plant species among Bedouin community in Wadi Allaqi. This is especially true for younger generations which rather orient themselves to new economic opportunities and urban lifestyles. On the other hand, Wadi Allaqi Bedouins at the shores of Lake Nasser have developed a new knowledge base through adapting grazing systems and associated knowledge as a response to the environmental and socioeconomic changes that have occurred in the last decennia (Kandal et al. 2016, 2019).

In order to understand how Egyptian policies may overcome a thus far largely symbolic approach to TK, we will discuss and summarize the TK status in Wadi Allaqi as emerging from policy documents and interviews with local stakeholders by applying a SWOT-like analysis (Table 2) in which strengths and opportunities are weighed against weaknesses and threats of the current policy situation. 
Table 2 Results of a SWOT analysis on TK in Wadi Allaqi, Egypt

\begin{tabular}{|c|c|}
\hline Strengths (S) & Weaknesses (W) \\
\hline $\begin{array}{l}\text { 1. International and regional agreements related to TK } \\
\text { signed by Egypt }\end{array}$ & $\begin{array}{l}\text { 1. Absence of a TK policy framework } \\
\text { 2. Institutional ignorance of TK }\end{array}$ \\
\hline 2. Efforts on documenting TK & 3. Local parties' lack of interest in TK \\
\hline $\begin{array}{l}\text { 3. Current projects in Wadi Allaqi by the government, } \\
\text { private sector, and the NGO }\end{array}$ & $\begin{array}{l}\text { 4. Absence of incentives for collaboration between } \\
\text { different local parties }\end{array}$ \\
\hline $\begin{array}{l}\text { 4. Universities as sources of experts and research on } \\
\text { TK }\end{array}$ & $\begin{array}{l}\text { 5. Absence of university programs and school } \\
\text { programs }\end{array}$ \\
\hline Opportunities (O) & Threats $(\mathrm{T})$ \\
\hline \multirow{5}{*}{$\begin{array}{l}\text { 1. Draft law on a national TK policy } \\
\text { 2. Individual interest in TK among local parties } \\
\text { 3. Status of Wadi Allaqi protectorate as a Biosphere } \\
\text { Reserve by MAB (UNESCO program) }\end{array}$} & 1. Isolated geographic location of Wadi Allaqi \\
\hline & 2. Socioeconomic changes in Wadi Allaqi \\
\hline & 3. Movements of Bedouins to other places \\
\hline & 4. Low interest of young people in TK \\
\hline & 5. Loss of knowledge through aging people \\
\hline
\end{tabular}

\subsection{Strengths}

The international agreements signed by the Egyptian government (Table 2, S1) are strong and indicate a basic interest in the role of TK which can be elaborated as a next step in the recognition of TK. The positive international climate of TK and cultural heritages may potentially give opportunities for international funding for measures that may contribute to strengthen both the position of TK and the socioeconomic position of local Bedouin communities by, e.g., educational and environmental and health-directed actions. It requires regional, international, and global cooperation and orientation by making use of international agreements, such as the CBD and the Nagoya Protocol (Harhash 2012).

The preservation of TK also requires its documentation (Medaglia et al. 2014). Egypt has already taken here some initiatives in the context of its natural and cultural heritage and as a consequence of international obligations (EEAA 2015). This policy of TK-documentation may considered a strength (Table 2, S2), but it requires further elaboration.

An important condition for the use of TK in sustainable development is interest of its owners (Mcgregor 2014). Our interviews in Wadi Allaqi confirm insights from other papers (see for example Belal et al. 2009; Kandal et al. 2016, 2019) and show that Wadi Allaqi Bedouins do have an interest in local projects (e.g., agriculture by the government and mining by the private sector). This enables them to stay in Wadi Allaqi, which in turn supports the position of TK. In this context, the NGO El-Bisharaya \& Al-Ababda Association in Aswan has set up relevant projects on handicrafts in Wadi Allaqi involving especially Bedouin women, which may deliver financial benefits and contribute to Bedouin culture (Table 2, S3).

Another condition is academic interest in TK and its communities (Gaski 2013). Although educational curricula and research agendas do currently not focus on TK, there is a tradition of TK research (Briggs et al. 2003; Belal et al. 2009) which may be revived again. As Egypt is among the countries with the highest increase in scientific research output in the world in 2018 (Makri 2018), TK could be taken up as a research focus which in turn may contribute to its the preservation and use (Table 2, S4). 


\subsection{Weaknesses}

Despite these strengths, there are also current weaknesses. A clear TK policy framework is lacking as TK is only rarely mentioned in the national policy documents and is hardly applied (Table 2, W1). Consequently, it has no role in most regional institutions (see Table 1, supplementary materials, Appendices of chapter five). This has resulted in institutional ignorance of TK (Table 2, W2), and as a consequence in a lack of interest and use by Wadi Allaqi sectors, we have investigated by interviews (Table 2, W3). We found a lack of cooperation between local actors from the different sectors in Wadi Allaqi (Table 2, W4), although there is an official obligation to work together in order to develop the resources of the area for the benefit of the people (Springuel and Belal 2003).

Despite the potential strength built by relevant academic institutions, the current absence of TK in academic research and educational programs as well as in school programs is a weakness. Here, a lack of funding is especially unfortunate in view of the high costs of TK research in remote areas such as Wadi Allaqi (Table 2, W5).

\subsection{Threats}

We consider as threats those developments which may restrict the interest and further integration of TK in Egyptian policy. Paradoxically, the remoteness of Wadi Allaqi and its social isolation may have contributed to the conservation of its TK so far, but is also a threat as it may contribute to a further marginalization of the local society and to the policy ignorance of TK (Table 2, T1). It certainly accounts for the relative difficulty to travel to the area and hinders cooperation with, e.g., researchers and governmental employees.

At the same time, strong social-economic developments in recent decennia have occurred in Wadi Allaqi (Kandal et al. 2016, 2019) where Bedouins have given up their traditional lifestyle, neglecting their TK (Table 2, T2). Related to these developments is that some Bedouins tend to leave the area for a better living elsewhere which also results in the loss of TK (Table 2, T3). One aspect of these developments is decrease of interests in TK by the younger generation in Wadi Allaqi, preferring a more modern lifestyle at the cost of traditional knowledge and skills (Table 2, T4). As a consequence, much knowledge of, e.g., plant species, navigation, and grazing practices is found mainly among the elderly (Kandal et al. 2016, 2019) and is hardly passed on to the younger generation (Table 2, T5).

\subsection{Opportunities}

Finally, despite the weaknesses and threats, we have also indicated a number of opportunities for TK. One is that the Egyptian politics is currently finalizing a draft law on TK in relation to genetic resources (Table 2, O1). Although the current political condition has delayed this process, the draft version may still function as an opportunity to prepare measures that can be taken after the parliamentary approval (Table 2, O1).

Another opportunity is to make use of the individual interests in TK that we have noticed during our interviews with the local Egyptian policy-makers (Table 2, O2). Finally, we consider the UNESCO Man and the Biosphere Program as an outstanding 
opportunity for the development of TK in Wadi Allaqi. This intergovernmental scientific program facilitates the sharing of knowledge, promotes the interaction between science and society, and helps to bring concrete improvements to the lives of local populations. (UNESCO 2006). As such it may stimulate TK by offering funding opportunities (Table 2, O3).

\section{Recommendations}

Based on our SWOT analysis above, we would like to suggest a number of feasible policy directions and measures that may contribute to a better implementation of TK in Egyptian policy. Through connecting strengths and opportunities, weaknesses may be compensated or nullified, and threats are neutralized.

- First, it is mandated that the Egyptian Parliament approves a draft TK law in relation to genetic resources, which will result in a legislative effect for TK in general and facilitate its protection, conservation, and functioning in the governmental institutions.

- It is necessary to continue the process of TK documentation to get a complete database that could be transferred to the relevant institutions and may enhance cooperation and collaboration between governmental, academic, and NGOs, and thereby strengthen Egypt's natural and cultural heritage.

- Strengthening the research and educational systems and institutions on TK in Egypt should be given priority. Future research efforts should collect and quantify information on TK in collaboration with stakeholders including local communities by engaging them in discussions about TK. Such multi-actor, grassroots collaborations will contribute to health care, food security, sustainable agriculture and natural resource management, and related TK (Reo et al. 2017; Warren 1991).

- Without stable Bedouin communities, we run the risk of losing the current body of TK. TK policies should therefore be connected with an improvement in the socioeconomic situation of the Bedouin community. Younger generations of Bedouins should be involved in developing new opportunities for livelihoods.

- Additionally, it will be important to raise awareness in the Egyptian society as a whole by the dissemination of information such as books, CDs, TV and radio programs, and Internet sites. At the same time, one has to make sure that Egyptian institutions should be encouraged to relate these recommendations to international discussions and initiatives on TK.

Supplementary information The online version of this article (https://doi.org/10.1007/s10668-020-01139 $-5)$.

Acknowledgements We are grateful to the respondents for sharing their time and knowledge. We thank Dr. H.J. van der Windt (University of Groningen) for his valuable comments and anonymous reviewers for helpful suggestions. This research was funded by Nuffic (the Dutch organization for internationalization in education).

Open Access This article is licensed under a Creative Commons Attribution 4.0 International License, which permits use, sharing, adaptation, distribution and reproduction in any medium or format, as long as you give appropriate credit to the original author(s) and the source, provide a link to the Creative Commons licence, and indicate if changes were made. The images or other third party material in this article are included in the article's Creative Commons licence, unless indicated otherwise in a credit line to the 
material. If material is not included in the article's Creative Commons licence and your intended use is not permitted by statutory regulation or exceeds the permitted use, you will need to obtain permission directly from the copyright holder. To view a copy of this licence, visit http://creativecommons.org/licenses/by/4.0/.

\section{References}

Abou Zid, S. F., \& Mohamed, A. A. (2011). Survey on medicinal plants and spicesused in Beni-Sueif, Upper Egypt. Journal of Ethnobiology and Ethnomedicine, 7, 18.

Anaya, J. (1996). Indigenous peoples in international law. New York: Oxford University Press.

Belal, A.E., Leith, B., Solway, J. \& Springuel, I. (1998). Environmental valuation and management of plants in Wadi Allaqi, Egypt. Final report submitted to international development research centre (IDRC) Canada.

Belal, A., Briggs, J., Sharp, J., \& Springuel, I. (2009). Bedouins by the lake: Environment, change, and sustainability in Southern Egypt (p. 184). Cairo: American Univ in Cairo Press.

Berkes, F. (1999). Sacred ecology. Traditional ecological knowledge and resource management. Philadelphia and London: Taylor and Francis.

Berkes, F., Folke, C., \& Colding, J. (2000). Rediscovery of traditional ecological knowledge as adaptive management. Ecological Applications, 10, 1251-1262.

Briggs, J., Dickinson, G., Murphy, K., Pulford, I., Belal, A. E., Moalla, S., et al. (1993). Sustainable development and resource management in marginal environments: Natural resources and their use in the Wadi Allaqi region of Egypt. Applied Geography, 13, 259-284.

Briggs, J., Sharp, J., Hamed, N., \& Yacoub, H. (2003). Changing women's roles, changing environmental knowledges: evidence from Upper Egypt. Geographical Journal, 169, 313-325.

CFFS (Conservation of Flora and Fauna Secretariat). (1997). Recommendations on the integration of two ways of knowing: Traditional indigenous knowledge and scientific knowledge. Retrieved September 30, 2016, from http://www.grida.no/caff/inuvTEK.htm.

Drew, J. (2005). Use of traditional ecological knowledge in marine conservation. Conservation Biology, 19(4), 1286-1293. https://doi.org/10.1111/j.1523-1739.2005.00158.x.

EEAA. (1997). Ministry of state for environmental affairs, egyptian environmental affairs agency, national biodiversity unit. Egypt first national report to the conservation on biological diversity. pp 82.

EEAA. (1998). Egypt national biodiversity strategy and action plan for biodiversity conservation, Egyptian environmental affairs agency. Ministry of state for the environment. Department of nature conservation, National biodiversity unit.

EEAA. (2005). Third national report on convention on biological diversity (Egypt) (in Arabic). Ministry of state for environmental affairs, Egyptian Environmental affairs agency, Nature conservation sector. October, 2005.

EEAA (2006a). Protected areas of Egypt: Towards the future. Ministry of state for environmental affairs, Egyptian environmental affairs agency, Nature conservation sector. pp 68.

EEAA. (2006b). Biodiversity conservation capacity building in Egypt. Report. Ministry of state for environmental affairs. Egyptian environmental affairs agency, Nature conservation sector. pp 164.

EEAA. (2008). Fourth national report. (Biological diversity) (In Arabic). Ministry of state for environmental affairs. Egyptian environmental affairs agency nature conservation sector.

EEAA. (2010). Egypt national environmental, economic and development study (NEEDS) for climate change. Ministry of state for environmental affairs, Egyptian environmental affairs agency, Climate change central department, under the united nations framework convention on climate.

EEAA. (2014). Egypt's fifth national report to the CBD. Egyptian Environmental Affairs Agency, Egypt. pp 221.

EEAA. (2015). Egypt national biodiversity strategy and action plan to 2030 (p. 195). Egypt: Egyptian Environmental Affairs Agency.

EEAA. (2016). Egyptian biodiversity strategy and action plan (2015-2030). Arab Republic of Egypt, Ministry of environment. This work was produced through UNDP, GEF, PIMS no. 4864. January 2016. pp 83.

EEAA. (2016). "Protectorates declared in the framework of Law 102 of year 1983". Retrieved November 25, from, http://www.eeaa.gov.eg/en-us/topics/nature/protectorates.aspx.

Elansary, H. O., Mahmoud, E. A., Shokralla, S., \& Yessoufou, K. (2015). Diversity of plants, traditional knowledge, and practices in local cosmetics: A case study from Alexandria, Egypt. Economic Botany, 69(2), 114-126. 
El-kahki, A. (2010). "Integrated plan for the development of Sinai natural reserves". Arabic. Al-Ahram evening Newspaper. 28/4/2010. Retrieved January 28, 2012, from, http://ahramonline.org.eg/articles. aspx? Serial $=127237 \&$ eid $=907$.

Gaski, H. (2013). Indigenism and cosmopolitanism: A Pan-Sami view of the indigenous perspective in Sami culture and research. AlterNative: An International Journal of Indigenous Peoples, 9(2), 113-124.

Gomaa, S. S. (1997). Environmental policy making in Egypt. Gainsville: University Press of Florida.

Green, L. (2007). The indigenous knowledge systems policy of 2004: Challenges for South African Universities. Social Dynamics, 33(1), 130-154.

Harhash, K.A. (2012). Action plan for implementing the convention on biological diversity's programma of work on protected areas. Arab Republic of Egypt. Submitted to the secretariat of the convention on biological diversity. Ministry of state for environmental affairs, Egyptian environmental affairs agency, Nature conservation sector. pp 49.

Howitt, R., \& Suchet-Pearson, S. (2006). Rethinking the building blocks: ontological pluralism and the idea of 'management.' Geografiska Annaler, 88B(3), 323-335.

Howit, R., Havnen, O. \& Veland, S. (2012). Natural and unnatural disasters: Responding with respect for indigenous rights and knowledges. Aboriginal policy research consortium international (APRCi). 167. htps://ir.lib.uwo.ca/aprci/167.

Humphrey, A. (2005). SWOT analysis for management consulting. SRI alumni association newsletter, December 2005. California: SRI International.

Ibrahim, M. (2000). Protected areas and biodiversity in Egypt (in Arabic). Journal of Assiut for environmental studies, 19, 73-107.

IDSC. (2011). Egypt's national strategy for adaptation to climate change and disaster risk reduction. The Egyptian cabinet, information and decision support centre, and the UNDP.

IDSC. (2017). IDSC team's World Bank supported study tour to PAF Bangalore on implementation of social accountability tools in monitoring \& evaluation. The Egyptian cabinet, information and decision support centre, and the UNDP.

IDSC. (2018). The information and decision support center. Retrieved June 2, 2018, from http://www.idsc. gov.eg

Johnson, M. (Ed.). (1992). Lore: Capturing traditional environmental knowledge. Ottawa, Ontario: Dene Cultural Institute and International Development Research Centre.

Kandal, H. A., Yacoub, H. A., Gerkema, M. P., \& Swart, J. A. A. (2016). Vanishing knowledge of plant species in the Wadi Allaqi desert area of Egypt. Human Ecology, 44, 494-504.

Kandal, H. A., Yacoub, H. A., Gerkema, M. P., \& Swart, J. A. A. (2019). Traditional knowledge and community resilience in Wadi Allaqi, Egypt. Journal of Arid Environments press. https://doi.org/10.1016/j. jaridenv.2019.05.015.

Mahmoud, T., \& Gairola, S. (2013). Traditional knowledge and use of medicinal plants in the Eastern Desert of Egypt: A case study from Wadi El-Gemal National Park. Journal of Medicinal Plants Studies., 1(6), 10-17.

Makri, A. (2018). Pakistan and Egypt had highest rises in research output in 2018. Global production of scientific papers hit an all-time high this year, estimates show, with emerging economies rising fastest. Nature International Journal of Science. https://doi.org/10.1038/d41586-018-07841-9.

Mcgregor, D. (2014). Lessons for collaboration involving traditional knowledge and environmental Governance in Ontario, Canada. AlterNative: An International Journal of Indigenous Peoples, 10(4), 340-353.

Medaglia, J.C., Perron-Welch F. \& Phillips, F. (2014). Overview of national and regional measures on access and benefit sharing. Challenges and opportunities in implementing the Nagoya protocol. Third edition. CISDL Biodiversity \& Biosafety Law Research Programme.

Mugabe, J. (1998). Intellectual property protection and traditional knowledge: an exploration in international policy discourse. Retrieved September 9, 2009, from http://www.wipo.int/tk/en/hr/paneldiscu ssion/papers/pdf/mugabe.pdf.

Mundy, P., \& Compton, J. L. (1991). Indigenous communication and indigenous knowledge. Development Communication Report, 74(3), 1-3.

Osita, I. C., Oneybuchi, I. R., \& Justina, N. (2014). Organizations stability and productivity; the role of SWOT analysis an acronym for strength, weaknesses, opportunities and threat. International Journal of Innovative and Applied Research, 2(9), 23-32.

Posey, D. A. (Ed.). (1999). Cultural and spiritual values of biodiversity. United Nations environment programme. London, UK and Nairobi, Kenya: Intermediate Technology Publications.

Reo, N. J., Whyte, K. P., McGregor, D., Smith, M. A. P., \& Jenkins, J. F. (2017). Factors that support Indigenous involvement in multi-actor environmental stewardship. AlterNative: An International Journal of Indigenous Peoples, 13(2), 58-68. 
Salama, H. (2011). Environmental awareness and conservation of biological resources in Egypt: A review of moves to improve the ethical management of our ecosystems. Biology International, 52, 48-58.

Sillitoe, P. (1998). Knowing the land: Soil and land resource evaluation and indigenous knowledge. Soil Use and Management, 14, 188-193.

Springuel, I., \& Belal, A. (2003). The Guide to Wadi Allaqi biosphere reserve management, UESD. Egypt: South Valley University.

Tobin, B. (2004). Case study 12: Towards legal protection of traditional knowledge: Lessons from Peru. Section 3: Traditional knowledge in an international Regime. SPC traditional marine resource management and knowledge information bulletin.

UNESCO. (2006). Sub-regional consultation meeting on biosphere reserves "Review and Future Perspective". Cairo, Egypt. UNESCO office in Cairo regional office for science and technology for the Arab states.

USAID. (2010). Egyptian environmental education and outreach program, Final Report.

Walker, B. H., Holling, C. S., Carpenter, S. R., \& Kinzig, A. (2004). Resilience, adaptability and transformability in social-ecological systems. Ecology and Society, 9(2), 5.

Warren, D.M. (1991). Using indigenous knowledge in agricultural development. World Bank Discussion Paper No.127. Washington, D.C.: The World Bank.

Wilcock, D., Brierley, G., \& Howitt, R. (2013). Ethnogeomorphology. Progress in Physical Geography, 37(5), 573-600. https://doi.org/10.1177/0309133313483164.

Yacoub, H. (2013). To what extent has conservation strategy succeeded in protecting the natural heritage in Egypt? Essays on heritage, tourism and society in the MENA Region. International conference "heritage, tourism and political changes in the MENA Region”. Tangier, Morocco. Ferdinand Schoningh, Paderborn.

Publisher's Note Springer Nature remains neutral with regard to jurisdictional claims in published maps and institutional affiliations. 